\title{
Use of Chemical Soll Additives to Stabilize Off-Road Vehicle Trails
}

\author{
J. N. Davis，J. E. Baier，J. P. Fulton，D. A. Brown，T. P. McDonald
}

\begin{abstract}
Off-road vehicle (ORV) use is an increasingly popular form of outdoor recreation throughout the United States. This form of motorized recreation, however, can sometimes lead to serious erosion of trail running surfaces, with resulting export of sediment into forested ecosystems causing environmental degradation. This project was conducted to determine the feasibility of using two types of soil amendments, an acrylic copolymer (Envirotac) and a lignin emulsion (Terrabind), as cementing agents to seal and harden ORV trails to reduce erosion and promote durability. The amendments were evaluated in controlled traffic tests on simulated trails in two slope classes - averaging $2 \%$ and $8 \%$, respectively. Simulated rainfall events of 1-h duration and intensity of $75 \mathrm{~mm} / \mathrm{h}$ were used to assess erosion potential. Results showed that both amendments increased total runoff from test plots on flatter slopes, but that sediment concentration was reduced. Net export of sediment was lower for treated plots than those not receiving any soil amendment. In further tests after a period of four months and at higher soil moisture content, the Envirotac treatment retained most of its ability to control the sediment concentration of effluent while the effectiveness of the lignin product was reduced. The Envirotac product was selected for limited testing on actual ORV trails. The amendment was applied on curved, outsloped sections of trails and rut formation was compared to untreated curves located nearby. The soil amendment did not improve durability of the treated sections, but this was likely due to high soil moisture content at the time of installation.
\end{abstract}

Keywords. Erosion, Erosion control, Off-road vehicles, All-terrain vehicles, Rainfall simulator, Trail, Soil, Slope, Soil amendment.

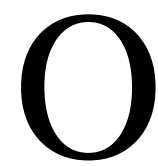
ff-road vehicles (ORV) have become a very popular form of recreation in the United States. The Forest Service estimated in 2004 that more than 11 million visitors attributed the primary or secondary purpose of their visit to a National Forest as ORV use (Bosworth, 2005). The Forest Service maintains about 36,000 miles of trails for ORV use, or about $28 \%$ of the total trail system. Cordell et al. (2005) found that almost 35 million people in the United States reported participating in some form of ORV recreation. They reported also Americans owned an estimated 8 million all-terrain vehicles and offroad motorcycles as of 2003, an increase of more than $170 \%$ over the previous decade.

With the increase in popularity of ORV recreation, a simultaneous decrease has occurred in accessible trail mileage. This has led to greater use pressure on the existing trail systems and, in some cases, degradation of the trails

Submitted for review in July 2006 as manuscript number SW 6579; approved for publication by the Soil \& Water Division of ASABE in April 2007.

The authors are Jonathan N. Davis, Project Engineer, Stantec Consulting, Macon, Georgia; James E. Baier, Assistant Professor, College of Agriculture and Human Ecology, Tennessee Tech University, Cookeville, Tennessee; John P. Fulton, ASABE Member Engineer, Assistant Professor, Biosystems Engineering Department, Auburn University, Auburn, Alabama; Dan A. Brown, Gottlieb Associate Professor, Civil Engineering Department, Auburn University, Auburn, Alabama; and Timothy P. McDonald, ASABE Member Engineer, Associate Professor, Biosystems Engineering Department, Auburn University, Auburn, Alabama. Corresponding author: Timothy $\mathrm{P}$ McDonald, 200 Corley Bldg., Auburn University, Auburn, AL 36849; phone: 334-844-3545; fax: 334-844-3530; e-mail: mcdontp@auburn.edu. themselves and the ecosystems in which they exist. Pressure from environmental advocates, and misuse of the trails by riders, has resulted in the Forest Service issuing new rules regarding when and how ORVs will be used on public lands (Federal Register, 2005). Off-road motorized recreation will, after an opportunity for public comment, be restricted to specific areas or trail systems, likely increasing pressure on available trails.

As the system of trails evolves to address the realities of an increasing population and the need to maintain a sustainable environment, new information on ORV trail management will be required in order to control both off-trail impacts and costs as use pressure increases. Important issues to be addressed include how to stabilize trail surfaces such that they can withstand heavy traffic pressure, minimize sediment export, and extend the period between intensive maintenance operations.

Several researchers have looked at the factors affecting degradation of walking trails (for example, Bratton et al., 1979; Bryan, 1977; Sutherland et al., 2001). In most cases, slope and soil type has been shown to have the greatest influence on amount of sediment export from hiking trails, although amount of traffic can also be a factor. In comparative studies, horse traffic caused greater damage by soil compaction and sediment export than human or llama (Deluca et al., 1998) and mountain bikes affected vegetative cover about the same as hiking (Thurston and Reader, 2001). Motorized vehicles have also been evaluated for their impacts on trails, and on soils in general. Adams et al. (1982) compared the negative effects of off-road truck and motorcycle traffic on soil compaction and subsequent vegetative growth in desert environments. They concluded that both types of vehicles compacted soils, but trucks to a greater 
extent. Kutiel et al. (2000) evaluated the effects of foot and motorcycle traffic on vegetation on sand dunes. Foot traffic above threshold levels (500 passes) decreased diversity of vegetation, whereas just one pass from a motorcycle reduced ground cover, as well as diversity. Eckert et al. (1979) compared motorcycle and truck traffic to undisturbed areas in desert soils and their response to simulated rainfall. They found that 50 passes by a motorcycle increased sediment export by two to four times over that found on undisturbed areas, depending on soil type. Truck traffic (20 passes) increased sediment by 3.5 to 20 times relative to controls. Foltz (2006) used simulated rainfall on ORV trails separated into three disturbance level classes to estimate sediment export. On trails located both east and west of the Mississippi River, disturbance level did not affect interrill erosion, which was found to be two to three times that of undisturbed ground at the same locations. Sack and da Luz (2003) found large amounts of sediment flux from ORV trails in Ohio, observed as changes in ground-height. Soils tended to be lost during periods of heavy traffic and to be aggraded when left undisturbed. They estimated net erosion rate from ORV trails to be about $2000 \mathrm{~kg} \mathrm{ha}^{-1} \mathrm{yr}^{-1}$ and noted that this result was similar to published values for erosion from trails in arid regions.

Information on ORV trail design to minimize maintenance has been published (Wernex, 1994; Fogg, 2002), although Leung and Marion (1996) state that this is the least-represented area of research in the literature. Design recommendations normally take the form of best management practices (BMPs) for a class of problems or concerns. In many situations, localized conditions - perhaps of soil, water, or use patterns - result in a particular trail section experiencing recurring, debilitating problems. Often these problems lead to severe rutting, ponding of water, and export of soil from the trail running surface onto adjacent forestland, or even into streams (Sack and da Luz, 2003). Repairing these problem areas is crucial from environmental, user safety, and rider enjoyment perspectives, but the cost can be quite high. Equipment is normally pulled from other high priority assignments, such as prescribed fire, to fix trails; that equipment is often not practical or appropriate for maintaining trails.

A far better alternative would be to construct trails such that these types of problems do not occur. In some cases, this ideal is simply not possible unless construction techniques more common in road building are used - addition of gravel or other tread surfacing materials, for example. Where water is also an issue, even gravel is not always sufficient to prevent trail surfaces from degrading.

Chemical soil stabilizers have been used in consolidating unpaved forest roads for some time (Rummer et al., 2001). This project was intended to evaluate their use in stabilizing ORV trails. The use of stabilizers to consolidate trails, if practical and effective, would give managers a tool to deal with problem areas. For example, soil amendments might be used to make trails relatively impervious to infiltration while retaining the characteristics ORV enthusiasts enjoy. Drainage structures often degrade quickly on trails, leading to conditions that promote rill erosion. Soil stabilizers could, for example, be used to harden water bars to withstand heavy traffic and continue to perform their erosion control function.

Soil stabilizers have been investigated as a means of decreasing erosion from exposed soil surfaces in agricultural and construction applications. In particular, polyacrilamide (PAM) has been evaluated as a means of controlling erosion in several studies. Flanagan et al. (2002) found that spraying a solution of PAM on steep slopes reduced erosion from simulated storms by $40 \%$ to $50 \%$. On flatter slopes (6\% to 9\%) Flanagan et al. (1997) found that application of PAM to soils effectively controlled rill erosion. Peterson et al. (2002) controlled erosion more effectively with solutions of PAM sprayed onto soils as opposed to granular application. In all these studies, the hypothesis was that PAM increased infiltration, reduced runoff, and therefore reduced erosion.

Increasing infiltration on ORV trails, however, is not a particularly useful outcome. Trail running surfaces must withstand intense disturbance from wheeled traffic. Increased infiltration would, at least temporarily, increase the moisture content of the soils and potentially lead to soil displacement and rut formation. The objective of this study was to evaluate the use of chemical soil stabilizers that tend to seal the soil surface. These products might be useful to managers in reducing the costs of maintaining trails and decreasing erosion impacts on their surroundings. Specifically, the study was intended to compare expected levels of soil erosion from experimental trails treated with one of two soil stabilization chemicals, an acrylic copolymer and a lignin emulsion, relative to untreated trails. A further objective was to gain experience in using the stabilizers on active ORV trails.

\section{Experimental Methods}

An experimental site in Tallapoosa County, Alabama, was chosen because of the proximity of varying slope conditions, uniform soil types, and the availability of an open, accessible area. The site was formerly cultivated, but had been in pasture for several years. From USDA maps, soils on the site were identified as either Cecil or Pacolet clay loams, with the former found on flatter slopes and the latter on the steeper regions. Both Cecil and Pacolet series soils are very deep, well drained, and moderately permeable. They are normally formed in Piedmont uplands with Cecil soils occupying low-lying areas and Pacolet soils the side-slopes of ridges. A textural analysis (Das, 2002) was performed using soils extracted from intact cores and indicated that, according to the Unified Soil Classification system, samples from both flatter and steeper slopes were a Silty-Clayey-Sand, and sandy loams according to the USDA textural triangle.

Eight simulated trail sections were installed on the site using a motor grader: four, in close proximity, on gently sloping ground and four on steeper ground. The motor grader scraped approximately $10 \mathrm{~cm}$ of soil/turf off the ground surface in straight segments, each about $60 \mathrm{~m}$ in length. These sections became experimental 'trails' within which each of four treatments was installed on $6-\times 3-\mathrm{m}$ plots $(32$ total plots: 2 levels of slope, 4 treatments, 4 replicates in a randomized complete block design, the trail being a 'block'). The treatments consisted of 1) a control, untreated section, 2) Envirotac applied using manufacturer's recommendations (CE), 3) Lignin applied using manufacturer's recommendations (Lignin), and 4) Envirotac sprayed onto the trail surface (SOE). All four treatments were assigned to plots within the trail sections in a random fashion. Average longitudinal slope was measured for each plot using a total station. Longitudinal 
slopes averaged $2.3 \%$ on the flatter trails, and $8.3 \%$ on the steeper trails.

\section{Amendment Comparison Criteria}

The purpose in using the soil amendments was to increase durability of ORV trails, but it was difficult to establish a reliable measure of trail 'durability.' The soils used in the controlled traffic tests were stable under the type of traffic applied, so displacement of soil was not considered a sensitive durability measure. It was concluded that total soil loss during simulated rainfall would be the best approach to detecting differences in the ability of the amendments to stabilize trail soils. The tested soil amendments were expected to increase trail surface cohesiveness and decrease permeability. The assumed benefit from these changes was reduced detachment of soil resulting from precipitation after vehicle traffic, observable as increased amount of runoff and lowered concentration of suspended sediment, with a net decrease in total sediment production.

\section{SoIl Amendments}

Envirotac is an acrylic copolymer manufactured by Environmental Products and Applications (Palm Desert, Calif.) primarily for dust abatement. Vinyl acrylic copolymer emulsions, similar to Envirotac, are used as base resins in latex paints. Terrabind, Inc. (Jupiter, Fla.) provided the lignin emulsion used in the study. It is a byproduct from the pulping industry and is most commonly used in stabilization of dirt roads (Rummer et al., 2001).

\section{Site Preparation and Treatment}

Half of the plots were treated with either of two soil amendments according to manufacturer's recommendations ('CE' and 'Lignin' treatments), summarized in table 1. Scarification was performed using a disc harrow. The lignin soil amendment solution was incorporated into plots with a PTO-driven, tractor-mounted rotary tiller. After spraying the soil amendment treatments on the scarified plots (and subsequent roto-tilling of the lignin plots), they were compacted using a small vibratory compactor and allowed to dry. On one plot in each simulated trail section (one quarter of the total), an Envirotac solution was sprayed directly onto unprepared soil (SOE treatment in table 1). Finally, one plot in each trail section was left unmodified and served as a control. After treatment installation, all plots were covered with plastic to allow time to cure. The amendment manufacturers recommended a curing time of $24 \mathrm{~h}$. For these tests, curing times were at least three months. Plots were covered when not being trafficked or measurements being taken. Cost estimates in the table were based on those incurred during the installation of the experimental plots and could be quite different for actual trails. In making the estimates, it was assumed that the soil amendments were being applied to existing trails so the motor grader costs were not included. The SOE cost included the expense for the Envirotac only, the price of which would undoubtedly be different.

\section{Soil Physical Property Measurements}

Before and after addition of the soil amendments, two soil cores of known volume were extracted from each plot to measure bulk density and moisture content. A dynamic cone penetrometer was used to estimate bearing strength of the treated and untreated plots. Measurements were made according to Forest Service guidelines (Douglas and Durward, 1992) and used to estimate a California Bearing Ratio (CBR) for the trails, a number accepted as a means of expressing the relative strength of sub-grade material in roads. Four dynamic cone penetrometer measurements were made on each plot, both before and after application of the soil amendment. Soil amendment treatments did not affect either subgrade CBR values or bulk density of the surface trail soils (averaged $5.5 \%$ and $1.35 \mathrm{~g} / \mathrm{cc}^{3}$, respectively).

\section{Simulated TrafFic}

Following application and curing of soil amendment treatments, the trail sections were trafficked 300 times using three vehicles: one each 250-cc and 125-cc 2-stroke off-road motorcycles, and a 425-cc 4-stroke 4-wheel-drive all-terrain vehicle. The number of passes for each vehicle was roughly equivalent. The riders went at a speed they were comfortable with, which tended to be quite fast and included rapid acceleration and deceleration at both ends of the trail sections. Two trails were trafficked at a time, with 150 passes made in each direction to equalize the amount of acceleration/deceleration on the end plots and number of passes in uphill and downhill travel (Weaver and Dale, 1978). Plots were again covered with plastic after trafficking.

\section{RAinfall Simulation}

Following trafficking, a rainfall simulator was used to apply water to the plot at a uniform rate for $1 \mathrm{~h}$ to a nominal depth of $75 \mathrm{~mm}$. This storm represented about a 50-year return period and should have been an event of sufficient intensity to highlight differences between the soil amend-

Table 1. Summary of soil amendment treatments.

\begin{tabular}{|c|c|c|c|}
\hline \multirow[b]{2}{*}{ Treatment Parameter } & \multicolumn{3}{|c|}{ Soil Amendment } \\
\hline & Envirotac II Acrylic Copolymer (CE) & TBI 66 Lignin Emulsion (Lignin) & $\begin{array}{c}\text { Envirotac II, Spray } \\
\text { Application Only (SOE) }\end{array}$ \\
\hline Pre-application soil treatment & Disc scarification & Disc scarification & None \\
\hline Dilution (water:amendment) & $3: 1$ & $1: 2$ & $2: 1$ \\
\hline Application rate & $\begin{array}{c}10-\mathrm{L} \text { solution } / \mathrm{m}^{2} \\
0.4 \mathrm{~m}^{2} / \mathrm{L} \text { Envirotac II }\end{array}$ & 7-L solution $/ \mathrm{m}^{2}$ & 8 -L solution $/ \mathrm{m}^{2}$ \\
\hline Incorporation method & Solution sprayed onto scarified soil & $\begin{array}{l}\text { Solution sprayed on scarified soil, } \\
\text { then rototilled to a depth of } 8-10 \mathrm{~cm}\end{array}$ & Solution sprayed onto bare soil \\
\hline Compaction & 2-3 passes with vibratory drum roller & 2-3 passes with vibratory drum roller & None \\
\hline Curing time & $24 \mathrm{~h}$ & $36 \mathrm{~h}$ & 12 to $24 \mathrm{~h}$ \\
\hline Estimated cost of treatment $\left(\mathrm{m}^{-2}\right)$ & $\$ 5.77$ & $\$ 8.71$ & $\$ 2.07$ \\
\hline
\end{tabular}


ment treatments. The simulator was $6 \times 3 \mathrm{~m}$, the same as the treatment plots, and applied water intermittently to control rainfall intensity. Nozzles were type 50WSQ.

Runoff was diverted to one corner of the plot using two channels cut into its edge, one each along the down slope longitudinal and lateral sides. The channels were lined with plastic and emptied into a calibrated H-flume that was used to measure flow rate.

A grab sample of runoff was taken every 5 min during the simulated rainfall along with a flow rate estimate. Total suspended sediment of the samples was measured using the methods described in Franson (1985). Portions of known volume (usually $30 \mathrm{cc}$, but varied depending on sediment concentration) from each grab sample were mixed thoroughly and vacuum filtered through a Whatman 934AH glass fiber filter. Filters were washed with de-ionized water, dried, and weighed before the process. After the sample was filtered through, the filter was dried and re-weighed.

\section{Tests at Higher Soil Moisture Content}

All trail sections (eight total) were trafficked and rained on, two trails at a time, over a period of about 12 weeks. Following the completion of these trials, it was decided to continue the experiment by adding an additional 300 traffic passes on a subset of the trail sections, about 4 months later during a wetter time of the year. Plots were left uncovered in the interim between tests. Those selected were three of the trails on the steeper sloping ground. Because the spray-only Envirotac (SOE) treatments had not performed as well as the other soil amendments (lower runoff - see table 2), and time to complete the fieldwork was short, the SOE treatments and one of the four trail replicates were eliminated from that round of experiments. Traffic application, simulated rainfall, and sediment loss measurements were conducted as in the previous experiments. Runoff was not measured in these tests because little infiltration occurred on the steeper plots and sediment concentration was most highly correlated with erosion losses.

To assess soil displacement due to traffic, lateral profiles across each plot were established before and after traffic using a string stretched between two fixed posts. Depth to the soil surface was measured at $8-\mathrm{cm}$ intervals across the plot. Data for each transect were expressed as total cross-sectional area of displaced soil.

\section{RESUlTS AND DisCUSSION} 300 Passes - Lower SoIL MoIsture

The first set of tests included all soil amendment treatments (compacted Envirotac, CE; Lignin; spray-only Envirotac, SOE) plus untreated controls. Soil erosion potential was assessed using simulated rainfall after 300 passes by ORVs. The effects of the three treatments on average sediment discharge over the 1-h rainfall are summarized in table 2 . Changes due to the treatments were observed in both runoff and sediment concentration, but the effect on total sediment exported from the plots was not dramatic. In fact, no statistically significant differences were observed between the sediment export rates on the $2 \%$ sloped plots. On the steeper slope, only the CE treatment export rates were significantly lower on average than the Control.
Table 2. Average sediment export values, by slope and treatment in initial testing.[a]

\begin{tabular}{|c|c|c|c|c|c|}
\hline \multirow[b]{2}{*}{ Variable } & \multirow{2}{*}{$\begin{array}{c}\text { Slope } \\
(\%)\end{array}$} & \multicolumn{4}{|c|}{ Treatment } \\
\hline & & Control & SOE & $\mathrm{CE}$ & Lignin \\
\hline \multirow[t]{2}{*}{ Runoff $[\mathrm{b}]$} & 2 & $0.64^{\mathrm{ab}}$ & $0.54^{\mathrm{a}}$ & $0.88^{b}$ & $0.91^{\mathrm{b}}$ \\
\hline & 8 & $0.96^{\mathrm{a}}$ & $0.93^{\mathrm{a}}$ & $0.99^{a}$ & $1.0^{\mathrm{a}}$ \\
\hline $\mathrm{TSS}[\mathrm{c}]$ & Combined & $2.76^{\mathrm{a}}$ & $1.91^{\mathrm{ab}}$ & $0.81^{\mathrm{c}}$ & $1.31^{\mathrm{bc}}$ \\
\hline \multirow[t]{2}{*}{ Total sediment $[\mathrm{d}]$} & 2 & $1.79^{a}$ & $1.38^{\mathrm{a}}$ & $0.91^{\mathrm{a}}$ & $1.34^{\mathrm{a}}$ \\
\hline & 8 & $5.50^{\mathrm{a}}$ & $2.93^{\mathrm{ab}}$ & $1.32^{\mathrm{b}}$ & $2.65^{\mathrm{ab}}$ \\
\hline
\end{tabular}

[a] Values within the same row with the same alphabetic superscript were not significantly different, $\alpha=0.1$.

[b] Units are dimensionless representing the ratio of total runoff to the amount falling on the plot in a given time period.

[c] Units are $\mathrm{g} / \mathrm{L}$.

[d] Units are $\mathrm{kg} / \mathrm{h}$.

Discharge was expected to be higher than control for treated plots on the flatter slope because of the sealing effect of the soil amendments. The plot-level results, summarized in table 2, showed a statistically non-significant increase in outflow for the $\mathrm{CE}$ and Lignin treatments relative to the Control. The SOE treatment, however, had significantly lower runoff than the other two soil amendments. This was considered a negative since infiltration of water would ultimately reduce the resistance of the trails to rut formation. On the $8 \%$ sloped trails, the trend was the same, but the magnitude of outflow was higher and more uniform and no significant differences were observed.

The poor performance of the SOE treatment in the first set of experiments was likely due to a problem, exhibited especially on the flatter-sloped plots, with the durability of the trail running surface. The depth of penetration of the soil amendment when sprayed onto the plots was evidently very shallow. In several places on the $2 \%$-sloped trails, it was observed that sheets of soil bound together with Envirotac but only a few millimeters thick were pulled off the SOE plot surfaces because of wheel spin of the trafficking vehicles. These sheets of soil tended to trap and hold runoff, causing ponding and increasing infiltration. This response would likely be detrimental to the durability of an ORV trail since increased infiltration would keep the trails wetter for a longer period of time, increasing the probability that traffic would eventually cause rutting. The same effect was much less pronounced on the steeper trails, probably because of the higher clay content of the surface soils.

The average suspended sediment concentration did not vary by slope (table 2). Among treatments, the CE soil amendment exhibited the lowest average concentration, significantly less than the Control and SOE treatments. The Control treatment concentration was highest, significantly more than the Lignin treatment but statistically the same as SOE.

On average, no differences were observed in total sediment export due to the soil amendment treatments on the $2 \%$ slopes. Suspended sediment concentrations, however, did show a response. The effect of reducing concentration on sediment export was masked by the increase in runoff observed on CE and Lignin treated plots. On the $8 \%$ slopes, runoff was higher and more consistent between treatments and the total sediment response mirrored that of the suspended sediment concentrations. The benefit of using 
these soil amendments would be greatest, therefore, on steeper trails.

Soil displacement on both slopes was consistently very small and considered negligible. No differences were observed in soil displacement among any of the amendments.

\section{Passes - Higher Soil Moisture}

Three trails on the $8 \%$ slope experimental plots were trafficked an additional 300 times (total of 600) and sediment export tests repeated, minus the SOE treatment. The results of the tests are summarized in table 3 . The CE plots had half the mean concentration of the control plots, but the difference was not statistically significant.

Unlike the initial tests at 300 passes, the Control treatment sections had a lower sediment concentration than the Lignin plots. Given that runoff characteristics did not change between tests, that is runoff was uniform among the steeper plots, the Lignin treatment was expected to have the highest total sediment export rate. In general, sediment concentrations in the second tests for all three treatments were about three to six times that of the previous.

Taken as a whole, results from the first tests indicated a beneficial reduction in sediment export from treating the experimental plots with the soil amendments. Discharge was increased, primarily on the flatter-sloped trails, but the concentration of sediment in the additional runoff was lower. The net effect was that total sediment outflow was reduced. The effect seemed to be equally beneficial from either the Lignin or CE treatments, as long as the manufacturer's recommendations were followed in their application.

In the second set of tests, a clear (but statistically non-significant) difference was exhibited in the sediment concentration between the CE and Lignin treatments. The second set of tests was performed about four months after the first, in the fall, and time and weather might have affected the hard surfaces created with the soil amendments. The lignin appeared to have broken down more quickly over time and lost its positive effect on surface strength. Significant rainfall had occurred in the hiatus between the two tests and the ground was definitely softer. Surface soil displacement, measured as changes in soil surface height, was larger on all treatments after the second tests than the first, but it was not necessarily correlated with the sediment concentration magnitude (table 3). The total cross-sectional area of the surface change was greatest for the Control treatment, less for the Lignin, and smallest for the CE. The mean area changes were of the same order of magnitude for the CE and Lignin treatment, but both were significantly smaller than the Control.

\section{Field Testing}

From the previous two testing projects, it was concluded that the compacted Envirotac (CE) treatment had the highest

Table 3. Mean suspended sediment concentration $(\mathrm{g} / \mathrm{L})$ and soil displacement (cross-sectional area) measured after 300 additional passes.

\begin{tabular}{lcc}
\hline Treatment & $\begin{array}{c}\text { Mean TSS, } \\
\mathrm{g} / \mathrm{L}(\text { Std Dev) }\end{array}$ & $\begin{array}{c}\text { Mean Rut Cross-Sectional Area } \\
\left(\mathrm{cm}^{2}\right)\end{array}$ \\
\hline Control & $6.41(2.97)$ & $-239^{\mathrm{a}}$ \\
Lignin & $8.12(4.69)$ & $-42.6^{\mathrm{b}}$ \\
CE & $3.47(0.46)$ & $-13.2^{\mathrm{b}}$ \\
\hline
\end{tabular}

probability of success when applied on an actual ORV trail. Although the Lignin treatment had performed about as well in initial tests, it seemed to break down more rapidly over time, as evidenced by higher sediment concentration in effluent from the plots relative to the CE treatment in the second tests. It also required an additional step when installing (roto-tilling) and more product per unit area of trail and costs were therefore higher.

Field testing was conducted on the Kentuck ORV trail, Talladega National Forest near Oxford, Alabama. The trail is a 25-mile network on steeply sloping ground. Maintenance is a never-ending problem for the trail's managers, primarily because of degradation of the running surface from heavy traffic. Curves in the trail are especially difficult to maintain. When maintenance work is performed on the trail, a dozer is typically used to outslope curved sections in order to shed water. Over time, however, the curves become rutted enough to start ponding water. At that point, any additional traffic leads to greatly accelerated rut formation, greater ponding of water, and a rapid disintegration of the running surface. These ponded areas can also become sources of a large amount of sediment export from the trail.

The CE treatment was applied here to test its ability to harden the trail running surface in curves. The test was not intended to provide a definitive answer concerning the worthiness of the treatment, rather it was an initial case study of the product in a specific application. It was hoped that lessons could be learned about treatment installation for larger-scale tests in the future.

Four curves were used in the tests, broken into two groups with a control and a treated section in each. The groups were formed by pairing curves based on similarity of radius and soils. The Forest Service used a small dozer to repair all four of the curves to what would be considered 'optimal' condition - outsloped and shaped for rapid drainage. Following the repair, two of the curves were treated using the Envirotac product (CE) according to manufacturer recommendations. These were: disking to scarify soil; applying $10 \mathrm{~L}$ of concentrate per $\mathrm{m}^{2}$ of trail surface diluted $4: 1$ with water followed by time enough to allow the solution to soak in (about $4 \mathrm{~h}-\mathrm{a}$ visual assessment); compacting with a small sheep's foot roller $(1360 \mathrm{~kg}$ ); curing for $48 \mathrm{~h}$ (manufacturer recommended 24).

Cross-sectional profiles were taken of each curved section at four locations from a reference line formed by a string stretched across the trail between posts sunk in concrete on either side of the trail. Profile measurements were taken immediately after curing, then at approximately two-week intervals for a period of about two months.

The results showed no benefit from using the Envirotac treatment. Rut formation was lower on one of the treated sections than its paired control segment, and higher in the other. Both treated sections had formed berms and ponded water at the end of the measurement period, the same as the untreated sections. Further, the apparent rate at which the ruts formed was no different between the controlled and treated trails. After seeing a benefit from the soil amendments in the controlled tests, it was surprising that they did not show any positive effect on actual ORV trails. The most likely cause for the poor performance of the soil amendments was felt to be the high initial moisture content of the soils on the trail. Because they were wet to begin with, and made wetter with the application of the soil amendment solution, the trails 
never had a chance to dry out and 'set' as they had in the controlled tests.

\section{SumMARY AND CONCLUSIONS}

Two soil amendment chemicals were evaluated for their ability to reduce sediment production from off-road-vehicle (ORV) trails. On trails sloping $2 \%$, average total sediment exported from the plots was not affected by soil amendment treatment. Runoff was increased on plots treated with both Lignin and compacted Envirotac (CE), but the suspended sediment concentration was lower and the net effect was no differences among any of the treatments. On $8 \%$ sloped plots, runoff was uniformly high regardless, but soil amendment treatment tended to reduce sediment concentration. The net effect in that case was that only the CE treatment significantly reduced total sediment exported relative to untreated plots. When experiments were repeated a few months later and at higher moisture content, the $\mathrm{CE}$ treatment reduced sediment concentration from simulated rainfall compared to the Lignin product.

Limited field-testing of Envirotac on actual ORV trails did not produce the results expected. The treated curved trail sections withstood the damaging effects of traffic no better than untreated trail sections. The likely cause of this was the high initial moisture content of the trail soils, which did not allow the amendment to cure sufficiently.

\section{ACKNOWLEDGEMENTS}

The authors would like to thank the Auburn University Environmental Institute, the Alabama Agricultural Experiment Station Piedmont Substation, Environmental Products and Applications, Inc. and the USDA Forest Service, Southern Research Station, Forest Operations Research Unit for financial and in-kind support. They would also like to thank the USDA Forest Service, National Forests of Alabama, Talladega National Forest for allowing the use of the Kentuck Trail system for the study and for their assistance in installing the treatment plots.

\section{REFERENCES}

Adams, J. A., A. S. Endo, L. H. Stolzy, P. G. Rowlands, and H. B Johnson. 1982. Controlled experiments on soil compaction produced by off-road vehicles in the Mojave Desert, California. J. of Applied Ecology 19(1): 167-175.

Bosworth, D. 2005. Forging a sustainable system of routes and areas for motorized use. In Off-Highway Vehicle Use and Collaboration: Lessons Learned from Project Implementation, 9-14. August 26: U.S. Institute for Environmental Conflict Resolution.

Bratton, S. P., M. G. Hickler, and J. H. Graves. 1979. Trail erosion patterns in Great Smoky Mountains National Park. Environmental Management 3(5): 431-445.

Bryan, R. B. 1977. The influence of soil properties on degradation of mountain hiking trails at Grövelsjön. Geografiska Annaler. Series A, Physical Geography 59(1/2): 49-65.

Cordell, H. K., C. J. Betz, G. Green, and M. Owens. 2005. Off-highway vehicle recreation in the United States, regions, and states: A national report from the National Survey on Recreation and the Environment (NSRE). Asheville, N.C.: USDA Forest Service, Southern Research Station.
Das, B. 1986. Soil Mechanics Laboratory Manual. New York: Oxford University Press.

DeLuca, T. H., W. A. Patterson, IV, W. A Freimund, and D. N Cole. 1998. Influence of llamas, horses, and hikers on soil erosion from established recreation trails in western, Montana, USA. Environmental Management 22(2): 255-262.

Douglas, R. A., and G. Durward 1992. The dynamic cone penetrometer and its use on forest roads. In Proc. of the $15^{\text {th }}$ Annual Council of Forest Engineers Meeting, 45-55. Corvallis, Oreg.: Council of Forest Engineers.

Eckert, Jr., R. E., M. K. Wood, W. H. Blackburn, and F. F. Peterson. 1979. Impacts of off-road vehicles on infiltration and sediment production of two desert soils. J. of Range Management 32(5): 394-397.

Federal Register. 2005. Travel management; designated routes and areas for motor vehicle use. Federal Register 70(216): 68264-68291.

Flanagan, D. C., L. D. Norton, and I. Shainberg. 1997. Effect of water chemistry and soil amendments on a silt loam soil - Part 2: Soil erosion. Transactions of the ASAE 40(6): 1555-1561.

Flanagan, D. C., K. Chaudhari, and L. D. Norton. 2002. Polyacrylamide soil amendment effects on runoff and sediment yield on steep slopes: Part I. Simulated rainfall conditions. Transactions of the ASAE 45(5): 1327-1337.

Fogg, G. E. 2002. Park guidelines for off-highway vehicles: a resource guide to assist in the planning, development enhancement, and operation of OHV recreation facilities. Arlington, Va.: National Recreation and Park Association.

Foltz, R. B. 2006. Erosion from all terrain vehicle (ATV) trails on National Forest lands. ASABE Paper No. 068012. St. Joseph, Mich.: ASABE.

Franson, M. A., ed. 1985. Standard Methods for the Examination of Water and Wastewater, $16^{\text {th }}$ ed. Baltimore, Md.: Port City Press.

Kutiel, P., E. Eden, and Y. Zhevelev. 2000. Effect of experimental trampling and off-road motorcycle traffic on soil and vegetation of stabilized coastal dunes, Israel. Environmental Conservation 27(1): 14-23.

Leung, Y.-F., and J. L. Marion. 1996. Trail degradation as influenced by environmental factors: A state-of-the-knowledge review. J. of Soil and Water Conservation 52(2): 130-137.

Peterson, J. R., D. C. Flanagan, and J. K. Tishmack. 2002. PAM application method and electrolyte source effects on plot-scale runoff and erosion. Transactions of the ASAE 45(6): 1859-1867.

Rummer, B., J. Klepac, H. Archer, and G. Hebner. 2001. Improving stability of low-volume forest roads using a lignin-based emulsion. In: Proc. of the $24^{\text {th }}$ Annual COFE Meeting, eds. J. Wang, M. Wolford, J. McNeel, 81-87. Corvallis, Oreg.: Council of Forest Engineers.

Sack, D., and S. da Luz. 2003. Sediment flux and compaction trends on off-road vehicle (ORV) and other trails in an Appalachian forest setting. Physical Geography 24(6): 536-554.

Sutherland, R. A., J. O. Bussen, D. L. Plondke, B. M. Evans, and A. D. Ziegler. 2001. Hydrophysical degradation associated with hiking-trail use: A case study of Hawai'iloa Ridge Trail, Oahu, Hawai'i. Land Degradation \& Development 12(1) 71-86.

Thurston, E., and R. J. Reader. 2001. Impacts of experimentally applied mountain biking and hiking on vegetation and soil of a deciduous forest. Environmental Management 27(3): 397-409.

Weaver, T., and D. Dale. 1978. Trampling effects of hikers, motorcycles, and horses in meadows and forests. J. of Applied Ecology 15(2): 451-457.

Wernex, J. 1994. Off-highway motorcycle and ATV trails: Guidelines for design, construction, maintenance and user satisfaction, $2^{\text {nd }}$ ed. Pickerington, Ohio: American Motorcyclist Association. 